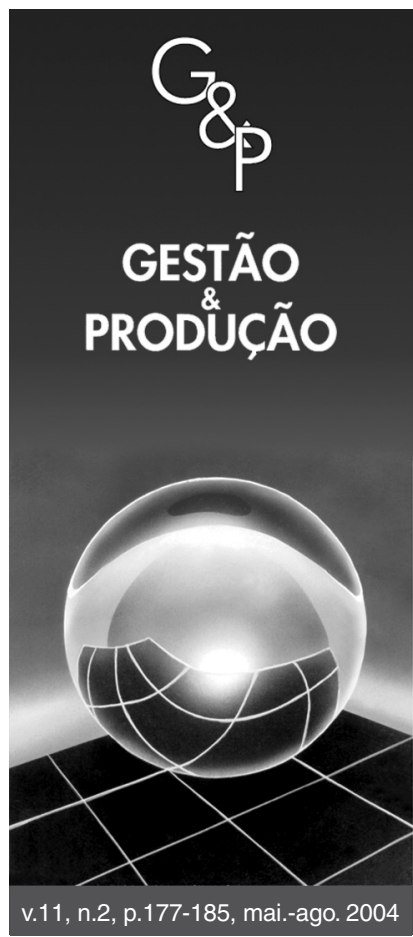

\title{
UMA AVALIAÇÃO DA LEI DE INFORMÁTICA E DE SEUS RESULTADOS COMO INSTRUMENTO INDUTOR DE DESENVOLVIMENTO TECNOLÓGICO E INDUSTRIAL
}

\author{
Renato Garcia \\ Departamento de Engenharia de Produção, Escola Politécnica da USP, \\ Av. Prof. Luciano Gualberto, travessa 3, n 380, CEP 05508-900, São Paulo, SP \\ e-mail: renato.garcia@poli.usp.br \\ José Eduardo Roselino \\ Instituto de Economia, UNICAMP \\ Cidade Universitária Zeferino Vaz, C.P. 6135, CEP 13083-970, Campinas, SP \\ e-mail: jose@ roselino.com
}

Recebido em 03/6/2003

Aceito em 10/5/2004

\section{Resumo}

Este trabalho apresenta um conjunto de considerações a respeito de alguns dos resultados da Lei de Informática sobre o complexo eletrônico brasileiro, a partir da análise dos seus efeitos sobre o desempenho de um conjunto de empresas que se beneficiam dos estímulos fiscais da lei. Apresentam-se aqui algumas reflexões críticas a respeito da eficácia e adequação deste instrumento para o desenvolvimento tecnológico do complexo eletrônico brasileiro.

Palavras-chave: política de ciência, tecnologia e inovação, complexo eletrônico, Lei de Informática.

\section{Introdução}

A Lei de Informática vigente é resultado de uma redefinição dos rumos da política industrial para o complexo eletrônico, ocorrida no início dos anos noventa. Este instrumento beneficia hoje um considerável número de empresas voltadas para atividades intensamente tecnológicas.

A concessão de benefícios fiscais prevista na legislação vincula-se à, por um lado, realização de esforços de pesquisa e desenvolvimento (P\&D) por parte das empresas em seus próprios departamentos de pesquisa, mas também em convênio com outras instituições. Por outro lado, está associada ao cumprimento dos requisitos do Processo Produtivo Básico (PPB), como forma de garantir internalização de etapas do processo de produção.

Muito embora estas exigências representem importantes iniciativas para o desenvolvimento tecnológico e industrial brasileiro, este instrumento tem se mostrado ineficiente no sentido de superar alguns importantes entraves para o desenvolvimento brasileiro, bem como para atenuar o problema estrutural do déficit comercial do complexo eletrônico no Brasil.

Para desenvolver esse argumento, o texto apresenta, na primeira seção, uma breve revisão da bibliografia principal sobre política industrial, procurando ressaltar a importância das formas de apoio do setor público ao desenvolvimento industrial e tecnológico. Em seguida, na Seção 2, são apresentadas as principais características da Lei de Informática. $\mathrm{Na}$ Seção 3, são relacionados os principais efeitos da lei, em termos da atração de investimentos internacionais ao setor, e da formação de capacitações locais, a partir dos esforços tecnológicos das empresas.

A análise dos efeitos da Lei de Informática sobre o complexo eletrônico brasileiro culmina na discussão das insuficiências dos incentivos sobre a atividade produtiva, especialmente sobre sua incapacidade de adensar a cadeia produtiva brasileira (Seção 4), e sobre os esforços tecnológicos (Seção 5). Por fim, são traçadas considerações finais.

Vale observar que parte das informações apresentadas no trabalho foi coletada a partir da participação dos autores em uma pesquisa coletiva, que envolveu visitas a empresas da região de Campinas (Suzigan et al., 2001). A amostra foi formada por doze empresas, e incluiu atores dos diversos elos das cadeias produtivas das indústrias de tecnologia de informação e comunicação, desde grandes empresas globais até firmas nacionais de menor porte. A circunscrição da amostra à região de Campinas é certamente um viés que não pode ser desconsiderado. 


\section{O papel e a importância da política industrial}

Em primeiro lugar, antes da avaliação dos efeitos da Lei de Informática sobre a indústria brasileira, mais especificamente sobre a cadeia eletroeletrônica no Brasil, é preciso definir claramente o papel e a importância da política industrial na promoção do desenvolvimento do setor produtivo de um país.

Desde logo, é importante destacar que a política industrial exerce efeitos muito importantes sobre a economia como um todo, ao promover a competitividade da indústria doméstica e contribuir na geração de emprego e renda, além dos efeitos positivos sobre a balança comercial.

Todavia, essa visão da política industrial não é unânime entre os autores. Para os autores mais ortodoxos, como Hayek (1949, citado por Chang, 1994), a intervenção governamental sobre as forças de mercado tem como único efeito a criação de "falhas de governo" (government failures), já que desvia o sistema econômico da trajetória em direção ao grau máximo de eficiência alocativa. Como apontaram Shapiro e Taylor (1990), a principal crítica ortodoxa à ação da política industrial está relacionada com a geração das chamadas government failure. A intervenção governamental sobre a estrutura produtiva, além de ter efeitos neutros sobre as "falhas do mercado" - market failure, acaba por gerar novas "falhas de governo", as government failures.

Há ainda um outro conjunto de autores, como Chang (1994) e Krugman (1993), que se afastam da tradição ortodoxa de interpretação do sistema econômico e entendem que a intervenção estatal tem efeitos positivos na correção de market failure, o que justifica a sua ação. Nesse caso, é admitido o uso de instrumentos de apoio ao sistema produtivo, porém tal intervenção deve ser restrita à correção das imperfeições de mercado, no sentido de sanar as falhas decorrentes da coordenação dos recursos, por meio do mecanismo de preços, e buscar a eficiência em termos alocativos. Suzigan e Villela (1997) chamaram essa abordagem de "enfoque restrito" da política industrial, já que para esses autores a ação governamental deve ser voltada exclusivamente à correção de falhas de mercado.

Em contraposição ao enfoque restrito de política industrial, é preciso investigar o que Suzigan e Villela (1997) chamaram de "enfoque abrangente" de política industrial. Dentre os principais trabalhos que se inserem nessa tradição, destacam-se os de Dosi (1988), Dosi et al. (1990), Corden (1980), Shapiro e Taylor (1990), Baptista (2000), além de Suzigan e Villela (1997). Para esses autores, a política industrial deve ser definida em um sentido amplo, que inclui não apenas medidas específicas à indústria, mas também políticas mais gerais (macroeconômicas e outras) que afetam a competitividade das empresas. Dessa forma, a política industrial deve ser focalizada para indústrias ou setores específicos, mas deve sempre procurar contribuir no processo de geração de vantagens competitivas para a indústria.

Dosi (1988) destaca que a política industrial deve agir sobre a atividade econômica de forma a criar vantagens com- petitivas baseadas na geração de novas tecnologias, buscando a eficiência dinâmica, mesmo que tenha que abrir mão da eficiência alocativa. Em termos de inserção internacional, a política industrial, ao estimular o incremento da competitividade sistêmica, estará imprimindo um caráter ativo à inserção internacional do país, ao contrário do caráter passivo verificado quando se busca a eficiência em termos alocativos. Como apontou Dosi et al. (1990), nenhum analista diria que, ao final da Segunda Guerra Mundial, um dos setores em que o Japão apresentava vantagens comparativas era a indústria eletrônica. Porém, a adoção de uma estratégia agressiva e consistente de política industrial pôde fazer com que fossem criadas vantagens competitivas nessa área.

Portanto, é preciso deixar clara a importância de políticas de desenvolvimento industrial e de promoção de substituição de importações. Políticas que visam a internalização de capacitações e mesmo capacidades produtivas devem ser apoiadas e estimuladas, pelos seus efeitos diretos em termos de geração de renda, emprego e comércio, como também pelos efeitos indiretos de transbordamentos (spill-overs) sobre a economia local.

Porém, tais políticas, por meio da concessão de incentivos, devem conter elementos virtuosos que promovam o desenvolvimento de capacitações locais. Para isso, devem ser capazes de atrair atividades geradoras de valor, principalmente pela criação de irreversibilidades que colaborem para a plena exploração dos benefícios que são gerados por tais ações.

\section{Política industrial no Brasil recente: A Lei de Informática}

As características da atual legislação de estímulo às atividades de P\&D, que compõe a chamada "nova lei de informática", foram definidas após o final do período de vigência da "reserva de informática", no início da década de noventa.

A indústria brasileira de componentes eletrônicos foi contemplada nos anos 80 , assim como diversas outras atividades do "complexo eletrônico", com um considerável aparato de proteção durante o período de vigência da "reserva".

A antiga "Lei de Informática" de 1984 garantia reserva de mercado para empresas de capital nacional nos oito anos seguintes, para a quase totalidade dos produtos e serviços relacionados às atividades de informática. Naquele contexto, o desenvolvimento de componentes apoiava-se em uma política de proteção ao "similar nacional" para os segmentos voltados aos equipamentos de pequeno e médio porte.

O desmonte da estrutura protecionista nos anos 90 é resultado da mudança de postura do governo brasileiro frente à ofensiva das pressões internacionais e nacionais, e objetivava remover os mecanismos regulatórios restritivos. No ano de 1990 ocorreu uma reforma administrativa que transformou a antes poderosa SEI (Secretaria Especial de Informática) em um "esvaziado" departamento do MCT (Ministério de Ciência e Tecnologia). Este evento representou o início da flexibilização e da posterior desmobilização da proteção à indústria nacional. 
O fim efetivo da reserva, em outubro de 1992, deixou o conjunto de atividades do complexo eletrônico sem um arcabouço institucional mínimo em relação à fabricação, desenvolvimento e comercialização de bens e serviços (Tigre, 1993).

A indústria nacional passou, desde então, por profundas transformações, adaptando-se a um regime consideravelmente novo, em que o protecionismo deu lugar a uma política que visava a remoção de proteções não-tarifárias, bem como a redução no nível e dispersão das alíquotas do imposto de importação. O início da década de 90 caracteriza-se assim por uma mudança expressiva rumo a um modelo mais aberto e desregulamentado.

Embora a definição de novas regras para o setor tenha ocorrido com a aprovação da Lei 8.248/91 em outubro de 1991, sua vigência efetiva inicia-se apenas com a regulamentação em 1993. Esta legislação eliminou as restrições anteriores ao capital estrangeiro e definiu uma nova política de estímulo centrada na obrigatoriedade de esforços mínimos em P\&D.

Esta legislação ocupou, desde então, parte do "vazio institucional" deixado pelo desmonte do aparato da política de informática. A definição deste novo regime deu-se ainda com o lançamento de programas governamentais, com enfoques mais restritos no início dos anos 90, como parte integrante de um projeto maior denominado DESI (Desenvolvimento Estratégico em Informática), que incorporava os seguintes "projetos prioritários" correlatos (MCT, 2002):

- Rede Nacional de Pesquisa - RNP, com a missão de desenvolver e implementar a infra-estrutura para a internet com fins acadêmicos;

- Programa Temático Multiinstitucional em Ciência da Computação - ProTeM-CC, articulando projetos de pesquisa consorciados entre a comunidade acadêmica e setor privado;

- Programa Nacional de Software para Exportação SOFTEX, que tinha como objetivo ampliar a presença do software nacional no mercado internacional; e

- Sistema Nacional de Processamento de Alto Desempenho, SINAPAD, que visava criar centros de prestadores de serviços de supercomputação no País.

Com a implementação da Lei 8.248/91, as atividades relacionadas à informática passaram a contar com uma política de incentivos fiscais vinculados à realização de esforços de P\&D no país.

Esta lei permitia às empresas localizadas fora da Zona Franca de Manaus gozarem de incentivos fiscais, obtidos pela isenção de IPI (da ordem de $15 \%$ para a maioria dos produtos incentivados). Como contrapartida, exigia a realização de investimentos equivalentes a $5 \%$ do faturamento bruto das empresas em pesquisa e desenvolvimento no país, bem como a observância das diretrizes do Processo Produtivo Básico (PPB), determinando as etapas mínimas do processo produtivo a serem realizadas no Brasil.

A aplicação desta legislação, e a aceitação desta pelas empresas, resultou em significativos valores investidos em P\&D durante sua vigência. Vale aqui sublinhar que este tipo de política é bastante diferente da que caracterizava o período da reserva de informática. Os instrumentos de estímulo e contrapartida, que compõem esta legislação, estão em sintonia com o novo ambiente competitivo de economia aberta e com a intensificação das relações comerciais internacionais - mesmo com o intensivo uso de comércio intrafirma. Este novo arcabouço institucional não apresenta os mesmos objetivos de substituição de importações do período anterior, mas, por outro lado, não faz recair sobre o consumo, os custos do esforço tecnológico exigido.

Assim, estas características apontam para uma pretensa "neutralidade" no freqüente conflito entre a busca de eficiência dinâmica e alocativa, resultando até em efeitos positivos sobre o preço final dos produtos incentivados. O ônus do esforço tecnológico recairia integralmente, neste novo modelo, sobre a receita fiscal da União.

Estima-se que no período 1993-2000 o montante acumulado destes investimentos tenha atingido $\mathrm{R} \$ 3$ bilhões, provenientes das empresas que operam em todo o território nacional (com exceção da Zona Franca de Manaus) (MCT, 2000). O Figura 1 apresenta a distribuição destes investimentos entre as Unidades da Federação, evidenciando a concentração de cerca de $2 / 3$ do valor total no Estado de São Paulo.

Este valor investido foi distribuído entre esforços de pesquisa na própria empresa (cerca de $\mathrm{R} \$ 2$ bilhões), em instituições de ensino e pesquisa (que ficaram com pouco menos de $\mathrm{R} \$ 1$ bilhão) e ainda recursos direcionados aos programas prioritários do MCT (SOFTEX, RNP e ProTeM-CC com $\mathrm{R} \$ 128$ milhões).

Ainda, conforme informações do MCT (2000), os benefícios foram concentrados em poucas empresas com elevados faturamentos. Do volume total de benefícios concedidos, $83 \%$ relacionaram-se com as atividades de apenas $30 \mathrm{em}-$ presas, sendo que as dez empresas com maiores valores receberam o equivalente a $61 \%$ dos benefícios totais.

Outra observação que se deve fazer é que é difícil precisar o montante de recursos direcionados para atividades

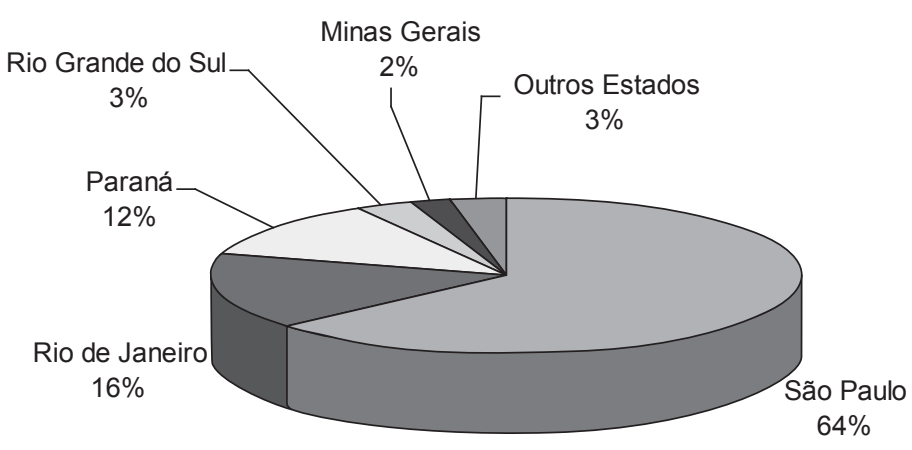

Figura 1. Distribuição por UFs dos Investimentos em P\&D das empresas beneficiárias de incentivos da Lei de Informática (1993-97). Fonte: MCT, 1998. 
efetivas em P\&D, uma vez que as empresas buscam, por vezes, enquadrar diversas outras atividades nesta conta. Durante o período, algumas empresas criaram instituições de pesquisa com identidade jurídica independente na forma de "fundações", para direcionar os investimentos exigidos em instituições de pesquisa.

Com o fim da vigência da Lei 8.248/91, aprovou-se, após um intenso debate entre os parlamentares e outros grupos políticos, uma nova legislação pertinente ao tema, a Lei 10.176/01, aprovada em 27 de dezembro de 2000 e sancionada no dia 11 de janeiro de 2001. Este instrumento mantém o mesmo espírito da lei anterior, ou seja, baseia-se na concessão de estímulos fiscais mediante $\mathrm{o}$ atendimento de obrigações relativas à realização de investimentos internos em P\&D.

A "nova Lei de Informática" estendeu os benefícios até o ano de 2009, aprimorando alguns aspectos da legislação anterior, na medida em que instituiu a obrigatoriedade de credenciamento das instituições habilitadas a realizar convênios, bem como uma política de desenvolvimento regional, que estabelece critérios geográficos para a destinação de parcela dos recursos investidos.

Para gozar plenamente dos benefícios previstos em lei, a empresa deve investir no mínimo 5\% de sua receita bruta em $\mathrm{P} \& \mathrm{D}$, obedecendo à seguinte distribuição: a empresa pode investir internamente $2,7 \%$ de seu faturamento. $\mathrm{O}$ restante $(2,3 \%)$ deve ser alocado em centros ou institutos de pesquisa ou educação (1\%), sendo, uma parte, obrigatoriamente, nas regiões Nordeste, Amazônica ou no Centro-Oeste $(0,8 \%)$ e parte, depositado no Fundo Nacional de Desenvolvimento Científico e Tecnológico - FNDCT. Pela forma de divisão apresentada, evidencia-se a preocupação da lei em não apenas estimular as atividades de $\mathrm{P} \& \mathrm{D}$ corporativo, mas também vincular os incentivos a formas de cooperação entre as empresas beneficiadas e universidades e institutos de pesquisa, numa estratégia deliberada de "enraizar" os esforços de desenvolvimento tecnológico, e provocar uma multiplicação dos transbordamentos de conhecimento associados aos investimentos.

\section{Efeitos da Lei de Informática sobre o complexo eletrônico}

A Lei de Informática representou, portanto, uma tentativa deliberada do governo brasileiro de estimular o estabelecimento no Brasil de empreendimentos ligados ao complexo eletrônico. Vale ressaltar que a lei contempla incentivos voltados à promoção da atividade tecnológica no Brasil (que se expressa na exigência de gastos em P\&D), mas também inclui uma preocupação com a nacionalização do processo produtivo, ao condicionar a concessão dos incentivos aos atendimentos dos requisitos do PPB.

Os resultados dessa política, de acordo com a versão oficial, podem ser considerados um sucesso. Segundo dados do MCT (2000), são mais de 200 empresas que gozaram dos benefícios da lei, o que se traduz em investimentos que atin- giram, como apontado, a casa de $\mathrm{R} \$ 3$ bilhões no período que vai de 1993 a 2001. Todas as atividades pertencentes ao complexo eletrônico podem gozar dos incentivos previstos na Lei de Informática. Dentre as 50 maiores empresas beneficiadas, 21 são produtoras de telequipamentos.

Além disso, a política de incentivos ao complexo eletrônico foi capaz de fomentar um processo de formação e consolidação de capacitações, por meio, principalmente, das interações com institutos locais de pesquisa. Nesse sentido, destacam-se as interações com instituições de pesquisa e prestação de serviços às empresas, com imenso destaque ao Centro de Pesquisa e Desenvolvimento (CPqD), do antigo sistema Telebrás. Algumas empresas de capital nacional até tiveram participação importante nesse processo, já que foram capazes de se aproveitar das interações com o $\mathrm{CPqD}$, para fomentar um processo endógeno de formação e acumulação de capacitações, que lhes permitiu inserir nas redes de fornecimento de equipamentos as operadoras de serviços de telecomunicações.

Nesse sentido, além da Lei de Informática, dois aspectos precisam ser ressaltados. Primeiro, a importância da proximidade geográfica das empresas e o CPqD, já que diversas dessas empresas estavam localizadas na região de Campinas. Conforma-se uma clara situação, na qual os produtores aproveitaram dos efeitos locais de transbordamento e da proximidade geográfica com o $\mathrm{CPqD}$. Além disso, muitas dessas empresas aproveitaram-se de capacitações formadas pelo centro de pesquisa, por meio da contratação de profissionais oriundos do $\mathrm{CPqD}$. Deve-se ressaltar a importância das interações locais para a formação do Pólo Tecnológico de Campinas, dada a existência de amplo aparato institucional na região, com efeitos expressivos em termos da formação de habilidades e competências que foram extensivamente utilizadas pelas empresas (ver Garcia 2000).

O segundo aspecto é que essas empresas de equipamentos de telecomunicações foram fortemente beneficiadas, até a privatização do sistema Telebrás, pela política de compras das empresas estatais operadoras de serviços de telecomunicações. Havia uma clara preferência pela compra de equipamentos que incorporassem tecnologia nacional, o que beneficiava os organismos locais de pesquisa (o CPqD especificamente) e as empresas que mantinham interações com esses organismos.

Isso permitiu o estabelecimento de empresas e de capacitações, que foram capazes de atender à demanda por equipamentos eletrônicos, especialmente de telecomunicações. Casos como os das empresas Promon, Zetax (ambas na região de Campinas) e Batik corroboram a importância desse processo para a formação de competências locais.

Outro caso interessante é o da empresa AsGa. Após uma ampla reformulação de suas atividades, a empresa abandonou algumas linhas e concentrou-se em alguns produtos específicos, que são fornecidos para, praticamente, todas as operadoras brasileiras de serviços de telecomunicações e, ainda, para as grandes empresas internacionais produtoras de equipamentos. 
Nesse sentido, a partir de esforços tecnológicos relevantes (a empresa gasta cerca de $10 \%$ do seu faturamento em P\&D), vem colhendo frutos positivos com a continuidade dos esforços de desenvolvimento de produtos com tecnologia nacional. Nesse caso, a Lei de Informática vem exercendo papel fundamental (assim como outras iniciativas públicas, especialmente na área do financiamento) para a dinâmica da empresa e para seus projetos de internacionalização.

Além disso, a Lei de Informática exerceu papel fundamental na atração de empreendimentos de grandes empresas internacionais do complexo eletrônico, tanto de equipamentos para telecomunicações (como Lucent, Motorola, Nokia, Siemens, NEC, Ericsson), como informática (Compaq, Texas Instruments). Foi responsável, também, pelo estabelecimento de uma rede de fornecedores locais, especialmente de empresas de manufatura (como Celestica, Solectron, Flextronics). Todas essas empresas declaram ter sido de fundamental importância a Lei de Informática, para a atração dos investimentos e para o estabelecimento desses empreendimentos no Brasil.

Por fim, ainda pode ser apontado um último efeito positivo da Lei de Informática sobre a economia brasileira. Algumas dessas empresas passaram a exportar parte dos produtos fabricados no Brasil, o que serviu para, principalmente, a partir de 2000, atenuar o déficit comercial do complexo eletrônico. Tal processo pode ser percebido pelas vendas externas de estações radiobase e sobretudo terminais celulares, que ultrapassaram a casa de US\$ 1 bilhão em 2002 (dados da SECEX/MDIC).

Portanto, os elementos apontados revelam o caráter virtuoso da política de incentivos ao complexo eletrônico, expressa por meio da Lei de Informática. Porém, outros fatores, que levariam a qualificar a importância da Lei de Informática, precisam ser incorporados ao debate, especialmente a forma como ela está desenhada, como elementos incentivadores do estabelecimento de atividades produtivas e tecnológicas na economia brasileira.

\subsection{Efeitos sobre a cadeia produtiva}

A avaliação do atual arcabouço institucional relacionado com a "Lei de Informática" constituída nos anos noventa (Lei 8.248/91), bem como sua substitutiva mais recente (Lei $10.176 / 01$ ), só pode ser realizada a partir de uma perspectiva que incorpore os elementos históricos e institucionais que marcaram a evolução do setor. Nesse sentido, o exame da eficácia da Lei de Informática na construção de capacitações domésticas no complexo eletrônico e no adensamento da cadeia produtiva do setor deve ser contextualizado.

A atração de importantes investimentos, nos segmentos das indústrias do complexo eletrônico, no período recente, está vinculada à existência de fatores de atratividade que foram constituídos no período anterior, marcado pelo protecionismo e pela forte presença estatal.

Assim, no segmento de telecomunicações, o desenvolvimento de capacitações locais não pode ser creditado como resulta- do da versão atual da legislação de informática, mas sim como resultado de uma política deliberada e centralizada do antigo sistema Telebrás, que, por meio da criação e da manutenção do $\mathrm{CPqD}$, conseguiu formar um conjunto de capacitações, que foram repassadas a empresas locais, tendo como exemplos mais exitosos o desenvolvimento das centrais Trópico, da tecnologia de fibra ótica e do cartão telefônico.

Vale ressaltar, neste sentido, o duplo papel desempenhado pelo sistema Telebrás: (i) financiamento direto do esforço de pesquisa; e (ii) política deliberada de compras junto às empresas domésticas. A importância deste papel no passado é ressaltada ainda pelo (quase) desmantelamento dessas capacitações após a privatização do sistema.

Dentre as empresas analisadas, e citadas no item anterior, podemos recolher evidências sobre os efeitos deletérios destas políticas, ao observarmos a drástica redução da participação no mercado da Promon/Trópico, bem como os destinos da Xtal, Batik e Zetax. Essas empresas perderam importância após a privatização do sistema Telebrás. A Promon deu origem a empresa Trópico S/A, criada a partir de uma jointventure com o $\mathrm{CPqD}$ (que deixou de ser organismo estatal de pesquisa, passando a ser uma fundação). Já a Zetax e a Batik foram adquiridas pela empresa estadunidense Lucent.

A trajetória da AsGa apresenta características bastante interessantes. Esta empresa soube redirecionar o seu foco (abandonando até mesmo a produção de componentes eletrônicos) para um nicho de mercado, e apresenta, atualmente, perspectivas promissoras. Os incentivos da Lei de Informática foram importantes, mas a sobrevivência desta empresa não teria sido possível sem a existência de linhas de crédito obtidas por meio de instituições oficiais (Finep, BNDES e Fapesp).

Deve-se considerar, ainda, que a atração das grandes empresas internacionais de equipamentos para telecomunicações, no contexto da privatização, esteve muito mais vinculada à perspectiva de expansão da demanda (comandada pelas operadoras de serviços e pelos requisitos da Lei Geral das Telecomunicações) do que com os mecanismos de estímulos promovidos pela Lei de Informática. Esse ponto deve ser ressaltado pela nova estrutura da oferta de serviços de telecomunicações, fortemente concentrada nas mãos do capital estrangeiro, cujas empresas têm recorrido aos seus fornecedores internacionais, agravando o déficit comercial do setor.

Outro aspecto merecedor de atenção é o que trata da utilização dos benefícios fiscais previstos na Lei de Informática, para as empresas de manufatura (as chamadas CEMs - Contracting Equipment Manufacturing), que são fornecedoras globais de serviços para as empresas de equipamentos (informática, telecomunicações e outros ramos do complexo eletrônico). Estas empresas são contratadas das empresas de equipamentos para realizar apenas a etapa da manufatura, já que o desenvolvimento e o projeto dos produtos são de responsabilidade do contratante. Sturgeon (2002), em sua análise sobre a indústria eletrônica estadunidense, mostra que, nessa forma de organização industrial, as empresas partici- 
pantes dessa relação, acabam por concentrar suas atividades em etapas específicas do processo de concepção, manufatura e comercialização dos equipamentos, aproveitando-se das economias e das sinergias obtidas pela especialização dos agentes.

A atividade destas empresas pouco representa em termos de desenvolvimento tecnológico, pois se trata de uma atividade desprovida de capacidades inovativas mais densas e de esforços de desenvolvimento de produto mais expressivos. Essas empresas "manufatureiras" realizam, em suas atividades no Brasil, os investimentos exigidos pela lei para a obtenção dos benefícios fiscais, direcionando $5 \%$ de seu faturamento em P\&D. Ocorre que estas empresas investem, mesmo em suas matrizes, valores significativamente menores em esforço tecnológico, pelas próprias características da atividade em que atuam. Podemos citar, por exemplo, o caso de duas das mais representativas empresas do ramo. A Celestica que investiu globalmente US\$ 17 milhões em P\&D no ano de 2001 (correspondendo a 0,2\% de seu faturamento), e a Solectron que apresentou gastos equivalentes, da ordem de $0,4 \%$ de seu faturamento no mesmo ano.

A inclusão destas empresas dentre as beneficiárias da "Lei de Informática", com a aplicação de 5\% do faturamento em $\mathrm{P} \& \mathrm{D}$, é certamente uma distorção provocada pela lei, uma vez que os benefícios concedidos são "contabilmente" atraentes, beneficiando empresas que não dedicam, em suas estratégias corporativas mundiais, tais volumes de recursos para a atividade de $\mathrm{P} \& \mathrm{D}$.

Em termos gerais, os investimentos em $\mathrm{P} \& \mathrm{D}$ presentes nestas atividades são estéreis em termos de internalização de novas capacitações. Os eventuais de transbordamento de atividades ligadas ao complexo eletrônico não são verificados neste contexto, já que as manufatureiras são subcontratadas globais das empresas produtoras de equipamentos, para a realização de atividades pouco significativas na "cadeia de valor" destes segmentos (Christensen et al., 2001). Mais do que isso, essas empresas são utilizadas como "colchão de amortecimento" das oscilações da demanda final, como comprovam as elevadas capacidades ociosas, que são verificadas quando das retrações das vendas desses produtos.

Outro ponto que merece comentários é o que trata da utilização do Processo Produtivo Básico - PPB, como referência para concessão de benefícios. Todas essas empresas, apesar de terem estabelecido no Brasil apenas processos de montagem de placa (o que é chamado de manufatura), não tiveram problemas no cumprimento dos requisitos mínimos exigidos. Nesse sentido, somente a montagem das placas e dos equipamentos já se mostrou suficiente para atender às necessidades de internalização da produção, o que é um indicador de inadequação do instrumento de apoio e de incentivos públicos.

Além do mais, outra observação crítica muito importante, que se faz ao atual aparato institucional, está, no entanto, relacionada à inadequação deste aos objetivos de equilíbrio da balança comercial do setor, e o decorrente adensamento da cadeia produtiva local de componentes eletrônicos (Tabela 1).

Frente a esses vultosos déficits na balança comercial do setor, provocados principalmente pelas importações de componentes - em especial semicondutores, a atual política não apresenta eficácia. Ou seja, a obrigatoriedade dos investimentos em P\&D e o PPB constantes na lei não têm sido suficientes para internalizar partes mais relevantes da cadeia produtiva, principalmente no que se refere à produção de componentes em território nacional.

A ênfase da legislação, que se seguiu ao desmonte da reserva de mercado, na internalizacão das atividades de $\mathrm{P} \& \mathrm{D}$, parece advir da consideração explicitada no documento do MCT (2002) de que "o desenvolvimento de produtos para novos mercados, ajuda a criar localmente

Tabela 1. Balança Comercial do Complexo Eletrônico - 1996/2000 (em US\$ milhões).

\begin{tabular}{lccccccc}
\hline Discriminação & $\mathbf{1 9 9 6}$ & $\mathbf{1 9 9 7}$ & $\mathbf{1 9 9 8}$ & $\mathbf{1 9 9 9}$ & $\mathbf{2 0 0 0}$ & $\mathbf{2 0 0 1}$ & $\mathbf{2 0 0 2}$ \\
\hline Importações & $6.480,5$ & $7.536,3$ & $6.833,2$ & $6.561,8$ & $8.747,5$ & $8.335,8$ & $5.507,5$ \\
Informática & $1.454,3$ & $1.461,3$ & $1.511,0$ & $1.426,7$ & $1.852,8$ & $1.715,6$ & $1.292,1$ \\
Eletrônica de Consumo & $1.037,1$ & $1.048,4$ & 622,8 & 370,6 & 411,5 & 342,7 & 407,4 \\
Telecomunicações & $1.925,2$ & $2.664,2$ & $2.578,7$ & $2.540,3$ & $3.155,9$ & $3.468,9$ & $1.437,2$ \\
Componentes & $2.036,9$ & $2.362,4$ & $2.120,7$ & $2.224,2$ & $3.327,2$ & $2.808,6$ & $2.370,8$ \\
Exportações & $1.006,2$ & $1.157,5$ & $1.153,1$ & $1.403,7$ & $2.452,5$ & $2.531,3$ & $2.360,3$ \\
Informática & 280,7 & 264,1 & 246,9 & 336,1 & 374,7 & 293,0 & 163,4 \\
Eletrônica de Consumo & 386,1 & 411,5 & 371,0 & 353,5 & 433,7 & 384,8 & 277,2 \\
Telecomunicações & 154,1 & 288,1 & 329,1 & 484,2 & $1.310,2$ & $1.547,9$ & $1.541,6$ \\
Componentes & 185,3 & 193,8 & 206,1 & 229,9 & 333,9 & 305,6 & 378,2 \\
Déficit & $5.474,0$ & $6.379,0$ & $5.680,0$ & $5.158,0$ & $6.295,0$ & $5.804,5$ & $3.147,1$ \\
\hline
\end{tabular}


a cultura da inovação, contribuindo para o crescimento auto-sustentado de longo prazo deste setor produtivo no país. Como o principal valor agregado não está na produção propriamente dita, a competitividade produtiva é que permitirá uma equação de viabilidade de exportação destes bens".

Esta afirmação é apenas parcialmente verdadeira, uma vez que o desenvolvimento internalizado de atividades de $P \& D$ não garante per se a internalização das etapas produtivas dos produtos aqui desenvolvidos. Em outras palavras, a realização de importantes atividades de pesquisa e desenvolvimento de novos produtos não necessariamente resulta (e não vem resultando) no estabelecimento de atividades produtivas mais relevantes, e mais geradoras de valor, dessas empresas no Brasil.

Pode-se citar como exemplo desta realidade a atividade de design de componentes de elevado valor agregado pela Motorola (contando ainda com a participação do CenPRA Centro de Pesquisa Renato Archer) na região de Campinas. São desenvolvidos protótipos de circuitos integrados no Brasil, que são, posteriormente, produzidos em série em outros países, resultando em quase nenhuma apropriação de resultados financeiros por parte da filial brasileira, ou mesmo, das contas externas do país.

Ocorre nesses setores um crescente "descasamento" geográfico entre as atividades de concepção e design e o processo produtivo propriamente dito, resultando em uma situação em que as atividades localizadas no Brasil, mesmo tendo evidente importância "técnica", não resultem em rendimentos proporcionais para a unidade local, nem para o balanço de pagamentos do país.

A inexistência de obrigações relativas a internalização de etapas produtivas mais densas nas cadeias de valor acaba restringindo os efeitos da Lei de Informática à potencialização de capacitações internas, geração de empregos qualificados (notadamente engenheiros empregados nos departamentos de $\mathrm{P} \& \mathrm{D})$ e demais efeitos de transbordamento. Além do mais, pode-se diagnosticar um problema significativo no que se refere à existência de vultosos "buracos" na cadeia produtiva do setor, como claramente demonstram os dados de comércio externo (Tabela 1).

Longe de desconsiderar a importância destes fatores, busca-se apontar a necessidade de se constituir mecanismos complementares mais efetivos no sentido de se adensar as estruturas produtivas locais, para fazer frente até mesmo à questão do elevado déficit destes segmentos.

No que se refere, por exemplo, à produção de componentes, um dos maiores responsáveis pelo déficit comercial do setor, a Lei de Informática foi incapaz de estimular a internalização de capacidade produtiva. Isso ocorreu seja pela ausência de escala para a produção desses insumos no país, seja pela incapacidade, pelos instrumentos existentes, de atrair empresas internacionais do setor ou de formar empresas domésticas capazes de suprir tal demanda (Amato et al. 2002).

\subsection{Caracterização dos esforços tecnológi- cos resultantes da Lei de Informática}

Um último indicador da insuficiência e da inadequação da Lei de Informática, no que se refere a objetivos mais ambiciosos da política de incentivos, refere-se ao caráter das atividades tecnológicas desenvolvidas pelas empresas internacionais produtoras de equipamentos, tanto de telecomunicações como de informática.

A análise dos esforços tecnológicos dessas empresas indica que se tratam, majoritariamente, de investimentos em laboratórios voltados ao desenvolvimento de software, que apresentam custos de instalação muito menores, relativamente aos centros de desenvolvimento de hardware. Nesse sentido, as empresas procuram atender aos requisitos da política de incentivo, em termos das atividades de $\mathrm{P} \& \mathrm{D}$, por meio de esforços em laboratórios de fácil desmobilização, o que reduz significativamente os "custos de saída" para essas empresas.

$\mathrm{O}$ direcionamento dos investimentos de $\mathrm{P} \& \mathrm{D}$, para o desenvolvimento de software, poderia até ser interpretado como um indicativo de que as atividades tecnológicas estariam voltadas para atividades mais "nobres" do esforço inovativo destas indústrias, visto que a importância do software é crescente e cada vez mais crucial, para todas as atividades de tecnologia da informação e comunicação. No entanto, a pesquisa de campo que subsidia este trabalho, corroborada pelas pesquisas de Galina (2003) e Roselino e Gomes (2003), indicou que as atividades desenvolvidas no Brasil são voltadas ao desenvolvimento de software de menor valor agregado, raramente gozando de alguma autonomia com relação às estratégias tecnológicas da corporação. Em reforço a esse argumento, pode-se citar que as atividades são normalmente voltadas à codificação e programação, e raramente incluem a arquitetura de sistemas mais complexos.

A Tabela 2 fundamenta este argumento, demonstrando

Tabela 2. Gastos em P\&D das empresas beneficiárias por destino (1993-99).

\begin{tabular}{lcc}
\hline Aplicação & $\begin{array}{c}\text { Valor } \\
\text { (R\$ Milhões) }\end{array}$ & Participação \\
\hline Desenvolvimento de Sistema & 603 & $27,05 \%$ \\
Desenvolvimento de Software & 518 & $23,24 \%$ \\
Desenvolvimento de Hardware & 237 & $10,63 \%$ \\
Treinamento em C\&T & 161 & $7,22 \%$ \\
Sistema de Qualidade & 146 & $6,55 \%$ \\
Laboratórios de P\&D & 108 & $4,85 \%$ \\
Pesquisa & 101 & $4,53 \%$ \\
Programas Prioritários & 100 & $4,49 \%$ \\
Desenvolvimento de PPB & 96 & $4,31 \%$ \\
Serviços de C\&T & 73 & $3,28 \%$ \\
Transferência Tecnológica & 37 & $1,66 \%$ \\
Desenvolvimento de Componentes & 25 & $1,12 \%$ \\
Outros & 24 & $1,08 \%$ \\
\hline
\end{tabular}

Fonte: Senado Federal (2000). 
que a grande maioria dos investimentos é direcionada para atividades como o desenvolvimento de sistemas e software, bem como a participação relativamente menor de atividades relativas à componentes e hardware.

Isso é justificado, em parte, pela incerteza acerca da manutenção dos incentivos, o que certamente inibe investimentos mais robustos. Uma prova disso é que, durante o período em que a nova lei não esteve vigente, verificou-se uma significativa redução nos novos investimentos das empresas do setor.

Porém, parece razoável supor que se trata de uma estratégia deliberada das grandes empresas internacionais do setor, que gozam dos benefícios da Lei de Informática, de não criar irreversibilidades relevantes. Isso lhes permite desmobilizar rapidamente os esforços locais de desenvolvimento tecnológico, de acordo com as estratégias definidas no âmbito da matriz e a manutenção do arcabouço institucional de incentivos.

Não se pode deixar de observar a existência de uma tendência à descentralização das atividades tecnológicas em nível internacional, já que muitas empresas têm procurado instalar laboratórios de desenvolvimento em outros países, buscando aproveitar-se, por um lado, de competências locais e, por outro, de vantagens de custos associadas a países com salários mais reduzidos. Mesmo assim, observa-se que os esforços de P\&D continuam concentrados nos países centrais, em especial nos países de origem do capital.

Conforme confirmado por Gomes (2003), identifica-se uma clara estratégia dessas empresas de elevar os investimentos de $\mathrm{P} \& \mathrm{D}$ fora do país de origem. As possíveis razões para isso são as tentativas de aproveitamento de competências locais (fora do país de origem) ou mesmo a busca de custos mais baixos dessas atividades em outras regiões - o que em grande parte explica a elevação dos gastos no Brasil.

Adicionalmente, é importante considerar a elevada renúncia fiscal associada a esta política, conforme o exposto no Figura 2.

O gráfico acima sugere ainda, uma perda relativa de eficiência da "Lei de Informática" como indutora de investimentos em P\&D por parte das empresas beneficiadas - como

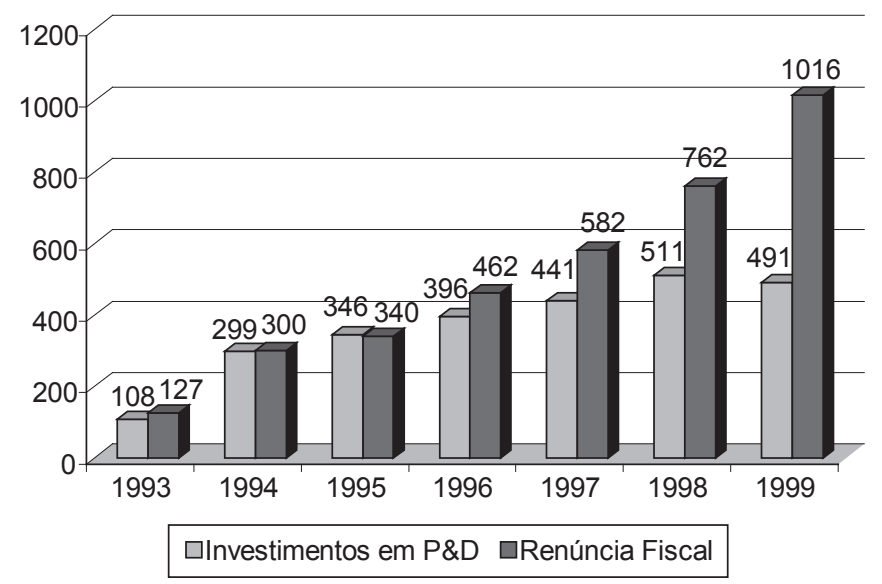

Figura 2. Investimentos em P\&D e Renúncia Fiscal relacionados com a "Lei de Informática" (1993-99) (R\$ milhões). Fonte: Senado Federal (2000). proporção da renúncia fiscal que ela proporciona. Isso se verifica, com base nos dados apresentados, pela redução dos valores empregados em $\mathrm{P} \& \mathrm{D}$ em relação à renúncia fiscal associada, já que o crescimento da concessão dos benefícios não esteve associado - ao menos proporcionalmente - à elevação dos investimentos em P\&D. Observa-se, por outro lado, um crescente "descolamento" entre o volume dos benefícios fiscais concedidos e o montante relativo ao benefício fiscal concedido.

\section{Considerações finais}

O exame dos principais efeitos da Lei de Informática, sobre a cadeia produtiva do complexo eletrônico brasileiro, revela sua importância na atração de empreendimentos de grandes empresas internacionais do setor, e no apoio de algumas iniciativas locais de estabelecimento de unidades de produção e de desenvolvimento tecnológico de empresas brasileiras.

Porém, do ponto de vista de uma política mais ambiciosa de desenvolvimento do complexo eletrônico no Brasil, a Lei de Informática tem sido insuficiente para a formação de capacitações no setor. Os desenvolvimentos tecnológicos mais importantes foram resultados de um amplo aparato institucional voltado ao desenvolvimento do setor, que foi constituído ao longo do período anterior.

Nesse sentido, é preciso questionar a eficácia da Lei de Informática na atração desses empreendimentos. No caso do segmento de equipamentos para telecomunicações, por exemplo, a privatização do Sistema Telebrás e a existência de um vasto potencial de mercado, garantido pelas metas de universalização dos serviços de telecomunicações, poderiam já ter sido suficientes para a atração dos grandes atores globais. Além do mais, a Lei de Informática não tem sido suficiente para estimular um maior adensamento da cadeia produtiva do setor, como mostram os vultosos déficits nas contas externas do complexo eletrônico.

Adicionalmente, pode-se argumentar que os esforços tecnológicos direcionados ao Brasil nos últimos anos, com a constituição de laboratórios de pesquisa de empresas transnacionais, não podem ser creditados como sendo resultados exclusivos da Lei de Informática, já que foram beneficiados também pela existência de uma tendência mundial de descentralização das atividades de P\&D nas grandes empresas globais.

Deve-se considerar ainda que este instrumento tem resultado em crescente e significativa renúncia, sem uma evolução correspondente nos valores relativos aos investimentos em P\&D.

São diversos, portanto, os fatores que concorrem para explicar, por um lado, o ingresso expressivo das grandes empresas internacionais produtoras de equipamentos para telecomunicações e informática no Brasil. Por outro lado, os efeitos locais de transbordamento de conhecimento e de tecnologia estão muito mais fortemente associados ao contexto institucional do período pré-privatização do sistema Telebrás do que com os incentivos da Lei de Informática - muito embora tenham sido apoiados por ela. 
Considera-se, então, que instrumentos de política industrial, como a Lei de Informática, são de fundamental importância para a promoção do desenvolvimento industrial e tecnológico em países de economia periférica como o Brasil. No entanto, estas políticas precisam ser direcionadas no sentido de se estabelecer um vínculo mais forte entre as atividades de $P \& D$ e a internalização de etapas produtivas associadas ao esforço inovativo.

\section{Referências Bibliográficas}

AMATO, J. et al. Análise das condições de desenvolvimento da indústria brasileira de semicondutores: texto para discussão. II Workshop Redes de Cooperação e Gestão do Conhecimento, São Paulo, PRO-EPUSP, http://www.prd.usp.br/redecoop/, 2002.

BAPTISTA, M. Política industrial: uma interpretação heterodoxa. Campinas: UNICAMP, 2000.

CHANG, H. -J. The political economy of industrial policy. New York: St. Martin's Press, 1994.

CORDEN, W. M. Relationships between macroeconomic and industrial policies. The World Economy, v. 3, n. 2, sep. 1980.

CRISTENSEN, C. M. et al. Skate to Where the Money Will Be, Harvard Business Review, v. 79, n. 10., nov. 2001.

DOSI, G. Institutions and markets in a dynamic world. The Manchester School, v. 41, n. 2, jun. 1988.

DOSI, G.; PAVITT, K.; SOETE, L. The economics of technological change and international trade. Brighton: Wheatsheaf, 1990.

GALINA, S. Desenvolvimento global de produtos: o papel das subsidiárias brasileiras de fornecedores de equipamentos do setor de telecomunicações. São Paulo: EPUSP. Tese de Doutoramento, 2003.

GARCIA, R. Experiências de clusters em setores de alta tecnologia: o caso da região de Campinas, São Paulo. Anais do V Encontro Nacional de Economia Política. Fortaleza, Set. 2000.

GOMES, R. A Internacionalização das Atividades Tecnológicas pelas Empresas Transnacionais. Campinas: UNICAMP.IE. Tese de Doutoramento, 2003.

KRUGMAN, P. The current case for industrial policy. In: SALVATORE, D. (ed.) Protecionism and world welfare. Cambridge: Cambridge Univ. Press, 1993.
MCT Setor de tecnologias da informação: resultados da Lei 8.248/91, http://www.mct.gov.br, 1998.

MCT Sociedade da Informação no Brasil: Livro Verde. Brasília, MCT, 2000.

MCT Tecnologia de Informação: Política Nacional de Informática, http://www.mct.gov.br/Temas/pni/pni.htm, 2002.

MELLO, P. et al. Complexo Eletrônico: perspectivas para o Brasil. BNDES Setorial, n. 13, Mar. 2001.

ROSELINO, J. E.; GOMES, R. O software e as cadeias produtivas internacionalizadas. In: FURTADO, J. (org.) Globalização das cadeias produtivas no Brasil. São Carlos: Ed.UFSCar, 2003.

SENADO Federal Aplicações em P\&D pelas empresas beneficiárias dos incentivos das Leis 8.248/91 e 8.387/91. http:// mct.gov.br/sepin/Palestras/EstudosRenuncia.htm, 2002.

SHAPIRO, H.; TAYLOR, L. The State and industrial strategy. World Development, v. 18, n. 6, 1990.

STURGEON, T. Modular production networks: a new American model of industrial organization. Industrial and Corporate Change, v. 11, n. 3, p. 451-493, 2002.

SUZIGAN et al. Inovação e difusão tecnológica em sistemas produtivos locais: evidências e sugestões de políticas, Relatório final de Pesquisa, FUNDAP, 2001.

SUZIGAN, W.; VILLELA, A. Industrial Policy in Brazil. Campinas: UNICAMP, 1997.

TIGRE, P.B. Liberalização e Capacitação Tecnológica: O Caso da Informática Pós-Reserva de Mercado no Brasil" IEI-UFRJ, 1993.

UNCTAD World Investment Report 2001. Genebra, UNCTAD, 2001. 


\title{
AN ANALYSIS OF THE LAW OF INFORMATICS AND ITS EFFECTS AS AN INSTRUMENT TO FOSTER INDUSTRIAL AND TECHNOLOGICAL DEVELOPMENT
}

\author{
Abstract \\ This paper analyzes some of the effects of the "Law of Informatics" on Brazil's electronics industry, based on an eva- \\ luation of its results on the performance of a group of companies benefiting from the law's tax incentives. Some critical \\ reflections are also made about the effectiveness and appropriateness of this instrument for the technological development \\ of Brazil's electronics industry.
}

Keywords: innovation policy, electronics industry, Law of Informatics. 